\title{
Información y consentimiento informado de menores de edad en Chile
}

\author{
FRANCISCO JAVIER LEÓN C. ${ }^{1}$ \\ 1. Doctor en Filosofía, Magíster en Bioética. Profesor Asociado Adjunto del Centro de Bioética, Facultad de Medicina, \\ Pontificia Universidad Católica de Chile.
}

\section{Introducción. El reto ético del consentimiento informado}

La noción de consentimiento informado se encuentra actualmente en el corazón de la medicina. Cada vez tenemos una mayor percepción de que los problemas de salud son más humanos que técnicos. El respeto hacia el paciente siempre ha presidido la práctica de la medicina, pero con la peculiaridad de que la capacidad de las personas para consentir o decidir no recibía un valor ético significativo. Hoy en día el profesional sanitario ejerce como experto en el cuidado de la salud, estableciendo para tal fin una alianza con sus pacientes. La actual avalancha de adelantos científicotécnicos brinda alternativas diagnósticas y curativas con diferentes probabilidades de éxito ligadas a costes y riesgos también variables.

Con el consentimiento informado no nos estamos limitando a un acto aislado y puntual como puede ser la aceptación de una prueba o un tratamiento. Nos estamos refiriendo a algo más amplio, a un modo de entender la relación clínica como un diálogo entre agentes morales. Las piezas fundamentales que componen la validez de este proceso de consentimiento informado son tres:

- La capacidad o competencia de la persona para adoptar decisiones responsables;

- la voluntariedad o libertad de coacciones externas o internas, y
- la información sustantiva o necesaria para que el paciente pueda decidir.

El reto que plantea el consentimiento informado es fundamentalmente ético, un auténtico ejercicio de estilo ético que es una expresión y una necesidad para promover la dignidad de la Medicina. Y es especialmente necesario en el caso de menores de edad, cuando legalmente corresponde a los padres representar los mejores intereses de sus hijos.

\section{Competencia e información al menor en la Ley chilena}

El texto, presentado en 2001 y revisado en el 2008, del proyecto de Ley de Derechos y deberes de las personas en la atención de salud, recogía en dos artículos, el $8^{\circ}$ y el $16^{\circ}$ todo lo relativo a la información y el consentimiento informado de menores de edad, con una proposición bastante novedosa tanto en Chile como en comparación con legislaciones de otros países $^{1}$. Aunque en la redacción final de 2012 se han suprimido estos párrafos, nos parece conveniente el análisis desde la ética.

Artículo 8: "Toda persona tiene derecho a ser informada, en forma oportuna y comprensible, por parte del médico u otro profesional tratante, dentro del ámbito que la ley autorice, acerca del estado de su salud, del posible diag-

Correspondencia a:

Francisco Javier León Correa

E-mail: fleonc@uc.cl 
nóstico de su enfermedad, de las alternativas de tratamiento disponibles para su recuperación y de los riesgos que ello pueda representar, así como del pronóstico esperado, y del proceso previsible del postoperatorio cuando procediere, de acuerdo con su edad y condición personal y emocional.

Dicha información será proporcionada directamente a los mayores de catorce años de edad y menores de dieciocho. Asimismo, el médico deberá, con consentimiento del menor, informar a los padres o representantes legales, o en su defecto, a la persona que lo tenga bajo su tuición o cuidado. En caso de que el menor no esté de acuerdo con que éstos sean informados, el médico consultará al comité de ética que corresponda, el que decidirá sobre la pertinencia de proporcionarles la información. Igualmente, se deberá informar a los menores de catorce años de edad, atendiendo sus condiciones de desarrollo psíquico, su competencia cognitiva y su situación personal, sin perjuicio de que se informe directamente, en los términos del inciso anterior, a los representantes legales”.

El Proyecto de Ley no contemplaba debidamente la posible falta de competencia o grado de madurez de las personas entre 14 y 18 años, como, sin embargo, sí lo hace con los menores de 14. Decide como norma general que el mayor de 14 años es competente no sólo para recibir la información o participar en el consentimiento informado, sino que le concede la facultad de decidir si su información clínica debe o no dársele a sus padres y si éstos deben participar o no en el proceso de consentimiento informado. La última palabra la tendría en todo caso, no el parecer prudente del médico o equipo tratante, sino el Comité de Ética, que por esto se convierte en mediador en problemas que no son estrictamente de ética clínica, sino producto de situaciones de confianza o desconfianza en el seno familiar.

Sin perjuicio de que el Comité de Ética pueda dar su consejo en casos especiales, pensamos que no debe ser norma general el recurso al Comité en estos casos, sino que su resolución debe darse en el ámbito de confianza de la relación médico-paciente, que debe incluir también a los familiares de todo paciente.

Por tanto, la propuesta sería: en caso de que el menor no esté de acuerdo con que sus padres o tutores legales sean informados o participen en el consentimiento informado, el médico decidirá atendiendo sus condiciones de desarrollo psíquico, su competencia cognitiva y su situación personal. En caso excepcional, puede el médico -como en cualquier otra situación de dilema ético-clínico- solicitar el parecer del Comité de Ética.

En la redacción final de la Ley de derechos y deberes de las personas en la atención de salud, se han suprimido estos dos párrafos, y no se dice nada acerca del consentimiento de menores, suponemos que para tratarlo aparte en un reglamento o normativa posterior.

Sin embargo, la misma ley, al hablar del derecho a la información, proporciona unas pautas aplicables a los menores. En el artículo $10^{\circ}$, tal y como ha quedado definitivamente, se expone: "Toda persona tiene derecho a ser informada, en forma oportuna y comprensible, por parte del médico u otro profesional tratante (...), de acuerdo con su edad y condición personal y emocional. Cuando la condición de la persona, a juicio de su médico tratante, no le permita recibir la información directamente o padezca de dificultades de entendimiento o se encuentre con alteración de conciencia, la información (...) será dada a su representante legal, o en su defecto, a la persona bajo cuyo cuidado se encuentre”.

Según esta redacción, se deja al arbitrio prudente del médico tratante la decisión de si conviene o no informar y a quienes.

De todos modos, en el Reglamento de Comités de Ética Científicos que supervisan la investigación, se recoge, en el artículo $11^{\circ}$ : "Toda investigación científica realizada con seres humanos deberá contar con el consentimiento previo, expreso, libre, informado y por escrito de la persona o, en su defecto, con el de aquel que deba suplir su voluntad en conformidad con la ley y en el caso de los niños menores de 18 y mayores de 12 se permitirá, en la medida de lo posible, su presencia al acto para conocer su opinión”.

Esta redacción permite la interpretación de que los menores podrán ser obligados por sus padres a participar en las investigaciones, lo que iría contra la Carta Internacional de Derechos del Niño, firmada por Chile. Los menores 
entre 14 y 18 años deben dar su consentimiento al protocolo de investigación según las pautas éticas de consenso internacionales.

Por otro lado va en contra del parecer de algunas sentencias recientes que -como en el caso del rechazo a una quimioterapia en un menor con cáncer- han revocado medidas que pretendían "el sometimiento forzoso al tratamiento de quimioterapia, respetándose de esta forma la decisión de la madre y del niño de optar por un tratamiento médico distinto, decisión que ha sido tomada fundada y razonadamente" 2 .

\section{Respeto a la autonomía y promover la competencia en menores}

Más allá de la competencia legal, reconocida o no suficientemente por la ley, están las normas éticas que pueden guiar al médico en el trato con menores, con el respeto a su autonomía que conlleva a la vez el deber de promover su competencia.

Se está planteando en todo el mundo, y también en Chile, una reducción importante en la edad en que podemos considerar competente al menor, especialmente en la comisión de delitos, responsabilidad de los actos públicos, elecciones de estilos de vida, etc., y también en la atención de salud. Hemos debatido si se puede o no entregar directamente a una menor la píldora del día después, o si en la consulta ginecológica puede venir sola sin un adulto, o si el médico puede hablar algunos aspectos a solas sin que estén en ese momento los padres o la madre delante.

Las reducciones en la edad del consentimiento no parecen basarse principalmente en suposiciones acerca de la capacidad de los menores. Más bien parece que su justificación habitual es permitir a los menores buscar y obtener tratamiento cuando es probable que la exigencia de que los padres den su consentimiento y se les notifique del caso desaliente a muchos de ellos de buscar tratamiento importante para su propio bienestar y el de otros ${ }^{3}$.

Por eso se aplica, se utiliza generalmente la "regla ética del menor maduro", como se contemplaba en el proyecto de ley chileno de
2008: se presume que los menores no tienen capacidad plena para dar su consentimiento a su propio tratamiento, pero se puede rechazar esa presunción demostrando su madurez, su comprensión de la naturaleza y objetivos del tratamiento propuesto. Pero la presunción va más allá: el análisis de la naturaleza de la determinación de capacidad, apoyada también por los estudios empíricos de las facultades de toma de decisiones de los niños y por la teoría del desarrollo, es que no se puede ya mantener como norma general que todos los menores son incapaces para decidir sobre la atención médica.

Por tanto, se defiende la presunción de capacidad extendida a los menores entre 14 ó 15, y 17 años, como se recoge en la mayoría de las leyes más recientes sobre derechos de los menores o los derechos y deberes de los pacientes en varios países.

Pero al contrario también, una presunción de capacidad extendida a los jóvenes de catorce a diecisiete años sería, tal como sucede con los adultos, sólo una presunción y así se podría rechazar en un caso particular si se aportaran elementos de prueba relacionados con la toma de decisiones del menor en ese caso. Esta presunción de capacidad abarcaría tanto consentir el tratamiento sin necesidad del consentimiento de los padres, como rechazar el tratamiento al que los padres del niño pudieran estar dispuestos a dar su consentimiento.

Para menores de catorce años, parece una buena razón material mantener la presunción actual de incapacidad ya que, en esa etapa, varias facultades generales de toma de decisiones suelen estar todavía pasando por un desarrollo importante.

\section{Voluntariedad del menor}

Además de la competencia, es necesaria la voluntariedad en el consentimiento informado, tanto con adultos como con menores de edad. Hasta ahora esto se suele reconocer en el asentimiento dele menor que se exige cuando los padres firman el consentimiento. Es evidente que los padres son los primeros encargados de la educación de sus hijos y que tienen bastante 
que decir en cuanto a los valores que desean trasmitirles, pero también tiene límites la patria potestad, especialmente cuando los menores ya son adolescentes, que sólo podrán madurar en la medida en que se responsabilicen de sus actos y aprendan a ejercer su libertad.

Es obvio que antes de los catorce años esta tarea de los padres es especialmente importante, aunque hay bastantes casos de menores de esa edad que comprenden perfectamente la información que puede darles el médico, y por eso, no se les puede dejar fuera de las decisiones que sobre ellos se tomen. Pero a partir de los 14, en nuestra opinión, ya es exigible que el adolescente tome las decisiones por sí mismo, ayudado por sus padres y por el médico tratante en lo posible, pero no coaccionado ni por sus padres ni por el médico. La coacción -además de ser por lo común muy contraproducente en esas edades- no deja ejercer la autonomía personal, ni por tanto, la responsabilidad ante las decisiones que otros toman por ellos.

Pensamos, por tanto, desde la ética y dejando aparte ahora lo que diga la legislación pertinente, que el consentimiento informado entre los 14 y 18 años deben firmarlo el propio menor $y$, en lo posible, uno de sus padres o tutores legales o los dos. En casos de conflicto, debe guiar al médico la voluntariedad del menor, junto con la consideración de su debida competencia, parcial, no plena, pero suficiente para el grado de decisiones que está tomando ${ }^{4}$. En casos de posible peligro para su vida o complicaciones que afecten gravemente a su salud, la decisión no podría tomarla sólo.

El médico pediatra debe ayudar a que el menor maduro tome las decisiones con la mayor voluntariedad posible, sin coacciones internas, miedos, ideas preconcebidas y prejuicios, y sin coacciones externas, de su ambiente familiar o de su grupo de amigos. Con las sugerencias de las personas que le sirven de apoyo, de su familia y de sus amigos, pero sin coacciones ${ }^{5}$.

\section{La información al menor y la confidencialidad}

El tercer aspecto clave del consentimiento informado es la información sustantiva o necesaria para que el paciente pueda decidir. La in- formación al menor, incluso mucho antes de los 14 años, es necesaria y clínicamente muy efectiva, para que también puedan sentirse comprendidos en la situación por sus padres y por los profesionales de la salud que les atienden, sin "conspiraciones de silencio" por parte de nadie.

A partir de los 14 años, pensamos que al deber de informar se agrega el de resguardar debidamente la confidencialidad, que siempre es un deber para con el propio paciente. Esa confidencialidad debe tener en cuenta el derecho de los padres a saber cuando se produce una situación grave o que puede poner en grave riesgo la vida o salud futura de su hijo, pero también el derecho del menor maduro a resguardar algunos aspectos de su conducta que desea tratar solamente con su médico, en una relación de confianza médico-paciente.

Es más, el médico tiene la misión de educar en salud, que es especialmente importante en la adolescencia, y solamente puede realizarla con la confianza plena de sus pacientes menores de edad. Los padres son los responsables de crear un ambiente de confianza con sus hijos que lleve a la necesaria participación en las decisiones que éstos deben tomar y que vayan a afectar su vida, pero en ningún caso el médico es el confidente de los padres que puede sustituirles cuando esa relación de confianza pueda estar disminuida.

\section{Referencias}

1.- Texto del Primer Informe Proyecto de Ley que regula los derechos y deberes que las personas tienen en relación con acciones vinculadas a su atención de salud. Boletín no 4.398-11.

2.- Recurso 103/2009 - Resolución: 5231 - Secretaría: FAMILIA. Valdivia, 14-05-2009.

3.- Buchanan AE, Brock DW: Decidir por otros. Ética de la toma de decisiones subrogada. México: UNAM y Fondo de Cultura Económica; 2009.

4.- Oppliger AW, Bascuñán RML: Consentimiento informado. Percepción de médicos, enfermeras y padres sobre el proceso comunicativo. Rev Chil Pediatr 2011; 82 (3): 204-10.

5.- Mcnab ME, Beca JP: ¿Existen límites en la decisión de los padres sobre el tratamiento de sus hijos? Rev Chil Pediatr 2010; 81 (6) 536-40. 